\section{Assessment of genetic variation of 15 Thai elite rice cultivars using InDel markers}

\author{
Pattaraborn Moonsap ${ }^{1}$, Nutthalak Laksanavilat ${ }^{2}$, Piyama \\ Tasanasuwan ${ }^{2}$, Sureeporn Kate-Ngam ${ }^{3}$ and Chatchawan \\ Jantasuriyarat ${ }^{1,4^{*}}$
}

\begin{abstract}
Many elite rice varieties have been developed in the last decades by Thai rice breeders. No information about the genetic gene pool of these elite rice varieties is available. This study evaluated the genetic relationship of 15 elite Thai rice cultivars using Indel markers. Of the 133 markers screened, 44 were polymorphic. The PIC scores ranged from 0.06 to- 0.50. By the UPGMA clustering method, they were separated into three major groups. Several markers identified specific DNA bands to certain rice cultivars, e.g., RD0305 and Rd0806 detected DNA bands specific for four photoperiod-sensitive rice cultivars. The gene pool of 15 elite Thai rice cultivars was moderately wide, and some closely related rice varieties were observed. The clustering result was consistent with the breeding pedigree. The data of this study can be used for the sustainable development of elite rice varieties in the future.
\end{abstract}

Keywords: DNA marker, improved rice varieties, indel marker, genetic variation.

\section{INTRODUCTION}

Rice (Oryza sativa), one of the most important cereal crops in the world, is a staple food and the main source of nutrition of Thai citizens. Thailand has proposed to expand the area of rice production, by adding 500,000 hectares to the currently 9.2 million hectares of rice-growing areas. From 2014 to 2017, Thailand was the second largest rice exporter after India on the world market (Thai Rice Exporters Association 2018). Although Thailand is one of the largest rice producers and exporters, the grain yield per area is almost the lowest of all rice-producing countries, due to many factors, e.g., diseases and environmental stress (Meyer and Prasertsri 2007). In the past three decades, Thailand has developed many elite rice varieties to increase the yield and quality of rice production. However, no information about the population gene pool of these elite rice varieties developed in Thailand is available. Many of them have the same parents, indicating that they share the same gene pool. It is very important to understand the genetic relationships of these developed elite rice varieties to ensure the sustainability of a rice breeding program.

Genetic diversity plays a major role in plant breeding programs. Knowledge of the genetic relationships between the different accessions can be extremely useful in the development of efficient germplasm management and utilization strategies (Barrett et al. 1998.) The importance of this kind of information has been demonstrated in genetic fingerprinting and genotype selection programs (Fufa et al. 2005). Several molecular markers are available for genetic diversity
Crop Breeding and Applied Biotechnology 19: 15-21, 2019 Brazilian Society of Plant Breeding. Printed in Brazil http://dx.doi.org/10.1590/198470332019v19n1a03

\footnotetext{
*Corresponding author:

E-mail: fscicwj@ku.ac.th D ORCID: 0000-0002-7278-970
}

Received: 28 March 2018 Accepted: 09 October 2018

${ }^{1}$ Kasetsart University, Faculty of Science, Department of Genetics, 50 Ngamwongwan Rd., Ladyaw, Chatuchak, Bangkok, 10900, Thailand 2 Kasetsart University, Faculty of Science, Department of Zoology, 50 Ngamwongwan Rd., Ladyaw, Chatuchak, Bangkok, 10900, Thailand

${ }^{3}$ Ubon Ratchathani University, Faculty of Agriculture, Department of Agronomy, Warinchamrap, Ubon Ratchathani, 34190, Thailand

${ }^{4}$ National Research University-Kasetsart University (CASTNAR, NRU-KU), Kasetsart University, Center for Advanced Studies in Tropical Natural Resources, Bangkok, 10900, Thailand 
studies. Insertion-Deletion (InDel) markers result from the insertion of transposable elements, slippage in simple sequence replication or unequal crossover events (Britten et al. 2003). InDel polymorphisms can be easily detected based on polymerase chain reaction (PCR) fragment length polymorphisms (Bhattramakki et al. 2002). InDels are also deemed a major source of gene defects and a significant source of evolutionary change (Britten et al. 2003). Because of their high abundance, reproducibility, co-dominant inheritance, and extensive genome coverage, InDels have been applied successfully for the analysis of genetic diversity and population structure in many plant species (García-Lor et al. 2012, Ollitrault et al. 2012, Wu et al. 2013). They have also been widely applied for genotyping, QTLs mapping, mapbased cloning, and even marker-assisted selection, including Arabidopsis (Hou et al. 2010), rice (Patel et al. 2014), wheat (Raman et al. 2006) and citrus (García-Lor et al. 2012). Our objective in this study was to use InDel markers distributed throughout the 12 rice chromosomes so as to analyze the genetic diversity and relationships of improved Thai rice cultivars.

\section{MATERIAL AND METHODS}

\section{Plant materials}

Seeds of 15 improved Thai rice cultivars (Table 1) were collected and germinated in a tray filled with soil until the seedlings were 22 days old. Young and fresh leaf samples were collected for genomic DNA extraction.

Table 1. List of elite rice cultivars and their characteristics

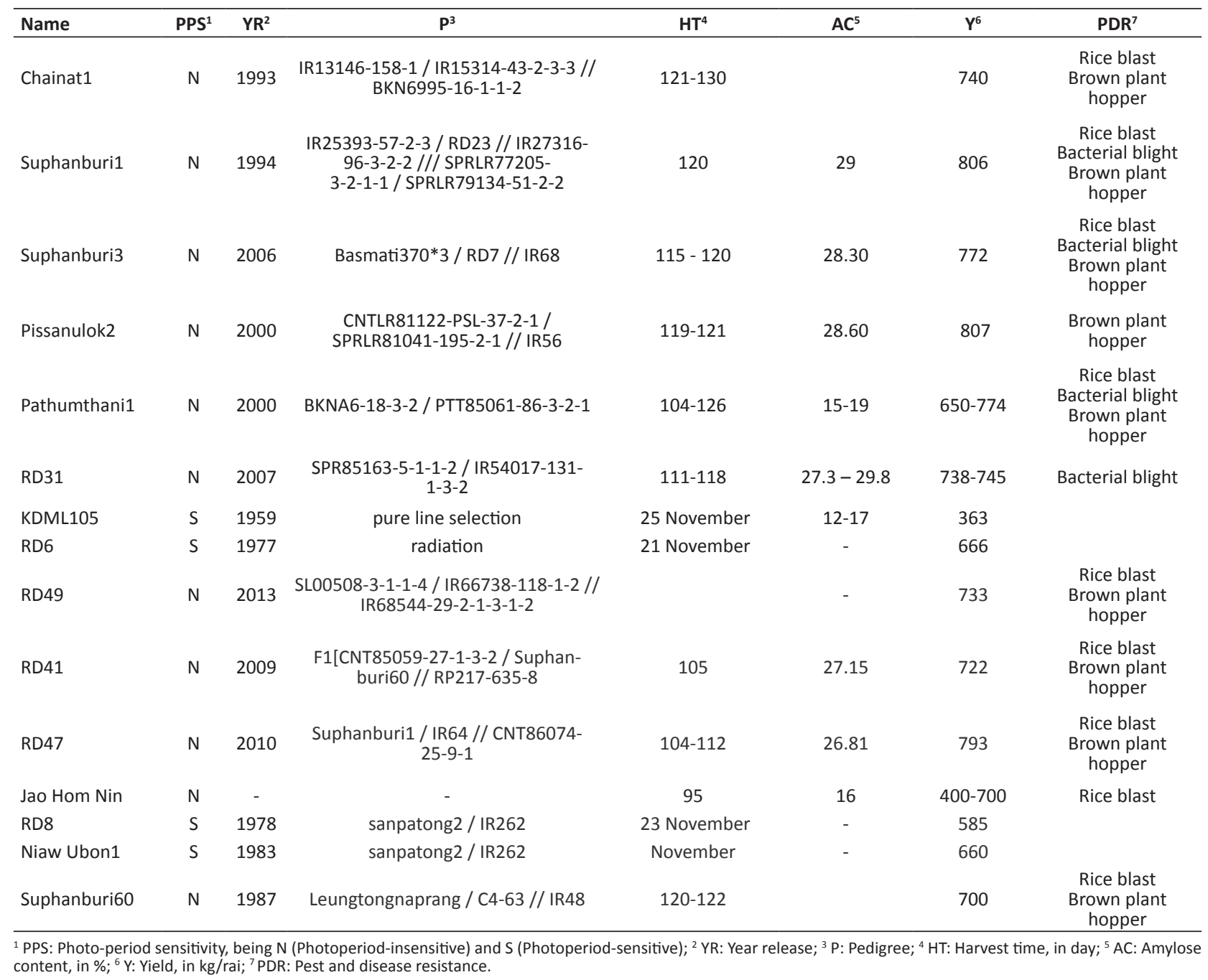




\section{DNA extraction}

For each rice cultivar, young leaves of five 3-week-old plants were pooled and used for genomic DNA extraction according to the modified CTAB method (Doyle and Doyle 1987). The quality and concentration of the DNA samples were checked by $1 \%$ agarose gel electrophoresis and with a NanoDrop spectrophotometer. The DNA samples were diluted to a final concentration of $50 \mathrm{ng} / \mu \mathrm{l}$ and stored at $-20^{\circ} \mathrm{C}$ until use.

\section{Indel analysis}

A total of 133 InDel primer pairs, which covered 12 rice chromosomes developed by Wu et al. (2013) were used. The PCR was performed in a total volume of $20 \mu \mathrm{L}$ as follows: $2 \mu \mathrm{L}$ PCR buffer (10x), $1.5 \mu \mathrm{L}$ dNTP mix (2.5 mM each), 0.3 $\mu \mathrm{L}$ Taq polymerase $\left(2.5 \mathrm{U} \mathrm{LL}^{-1}\right), 2 \mu \mathrm{L}$ forward primer and reverse primer $\left(10 \mu \mathrm{mol}^{-1} \mathrm{~L}^{-1}\right.$ each), $2 \mu \mathrm{L} \mathrm{DNA}$ template $(50 \mathrm{ng}$ $\mu \mathrm{L}^{-1}$ ), and $12.2 \mu \mathrm{L} \mathrm{ddH_{2 }} \mathrm{O}$. The amplification program was as follows: 5 min at $94^{\circ} \mathrm{C}, 35$ cycles at $94^{\circ} \mathrm{C}$ for $1 \mathrm{~min}, 55-60^{\circ} \mathrm{C}$ (depending on the primer) for $1 \mathrm{~min}, 72{ }^{\circ} \mathrm{C}$ for $2 \mathrm{~min}$, and a final extension of $10 \mathrm{~min}$ at $72{ }^{\circ} \mathrm{C}$. The PCR products were separated on $1.5 \%$ agarose gel. All InDel markers were repeated at least twice for each DNA sample.

\section{Data and statistical analysis}

The presence (1) or absence (0) of amplified DNA fragments were scored. The discriminatory power of each InDel marker was determined by calculating the polymorphic information content (PIC). The PIC was calculated according to the formula $P I C=1-\Sigma\left(f^{2}\right)$ where $f i$ represents the frequency of the ith allele of each InDel locus (Anderson et al. 1993). The genetic similarity coefficient, Nei-Li or Dice coefficient and Jaccard coefficient, with a bootstrap analysis of 1,000 for measuring pairwise band similarities between individuals was calculated, using the NTSYSpc version 2.01 (Rohlf 2000). Cluster analysis of the rice cultivars based on the genetic distance matrix was performed with the UPGMA (unweighted pair group method based on arithmetic averages) method (Sneath and Sokal 1973) using the SAHN function of the NTSYSpc version 2.01 to illustrate the genetic relationships. Tree Plot in Graphics was also used to draw a cluster analysis tree. Nei's gene diversity was calculated using POPGEN32 version 1.31 (Yeh and Yang 1999). Analysis of molecular variance (AMOVA) was performed to justify the suitability of group classification using program GenAlEx, version 6.5 (Peakal and Smouse 2012).

\section{RESULTS AND DISCUSSION}

\section{InDel marker polymorphism}

A total of 133 InDel markers distributed throughout 12 rice chromosomes were screened with 15 improved Thai rice DNA samples. Of these, 14 InDel markers were located on rice chromosome 1 . Ten InDel markers were located on rice chromosome 2 . Five, nine, nine, nine, eleven, eight, six, seven, seven and five markers were located on rice chromosome 3, 4, 5, 6, 7, 8, 9, 10, 11 and 12 , respectively (Figure 1 ). Ninty-nine markers (74.44 \%) successfully amplified rice genomic DNA and resulted in
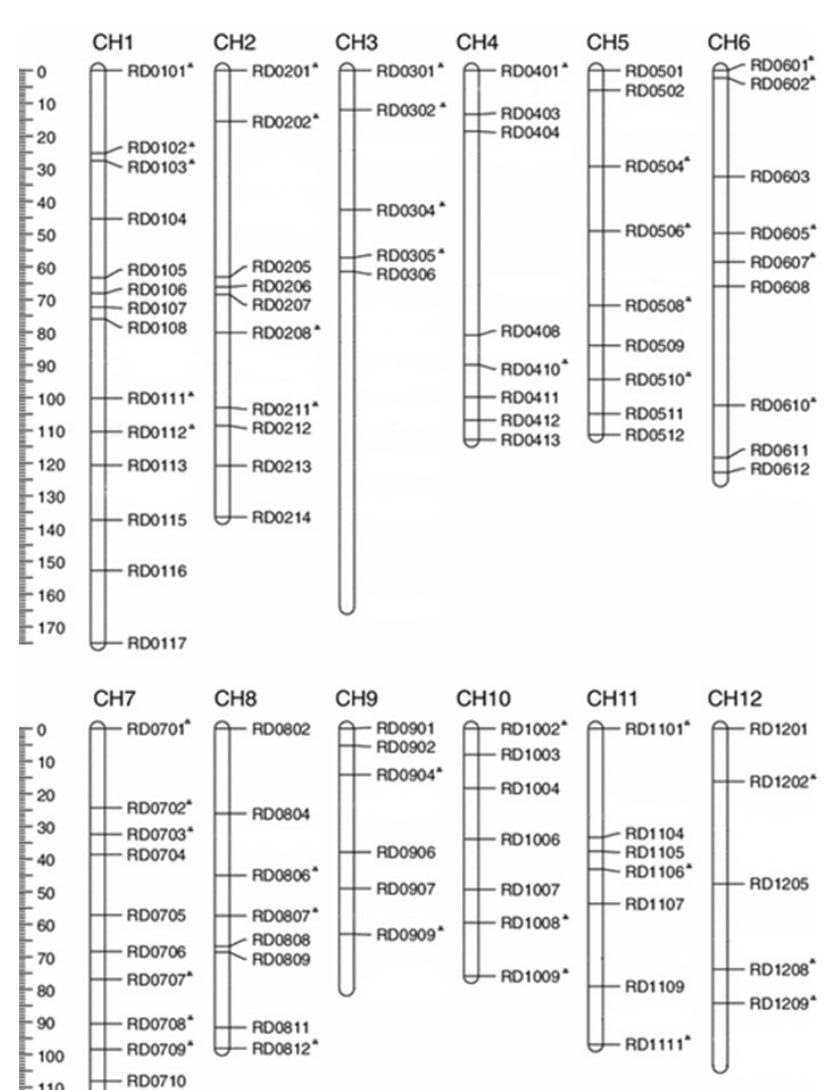
Table 2. Polymorphism in 15 rice cultivars revealed by InDel primers

\begin{tabular}{|c|c|c|c|c|}
\hline Chromosome & Primer & $\begin{array}{l}\text { No. of } \\
\text { alleles }\end{array}$ & $\begin{array}{l}\text { No. of polymorphic } \\
\text { bands }\end{array}$ & PIC \\
\hline \multirow[t]{5}{*}{1} & RD0101 & 2 & 2 & 0.41 \\
\hline & RD0102 & 2 & 2 & 0.12 \\
\hline & RD0103 & 2 & 2 & 0.32 \\
\hline & RD0111 & 2 & 2 & 0.23 \\
\hline & RD0112 & 2 & 2 & 0.12 \\
\hline \multirow[t]{4}{*}{2} & RD0201 & 2 & 2 & 0.28 \\
\hline & RD0202 & 2 & 2 & 0.48 \\
\hline & RD0208 & 2 & 2 & 0.46 \\
\hline & RD0211 & 2 & 2 & 0.28 \\
\hline \multirow[t]{4}{*}{3} & RD0301 & 2 & 2 & 0.32 \\
\hline & RD0302 & 2 & 2 & 0.32 \\
\hline & RD0304 & 2 & 2 & 0.39 \\
\hline & RD0305 & 2 & 2 & 0.39 \\
\hline \multirow[t]{2}{*}{4} & RD0401 & 2 & 2 & 0.44 \\
\hline & RD0410 & 2 & 2 & 0.12 \\
\hline \multirow[t]{4}{*}{5} & RD0504 & 2 & 2 & 0.12 \\
\hline & RD0506 & 2 & 2 & 0.50 \\
\hline & RD0508 & 2 & 2 & 0.46 \\
\hline & RD0510 & 2 & 2 & 0.44 \\
\hline \multirow[t]{5}{*}{6} & RD0601 & 2 & 2 & 0.12 \\
\hline & RD0602 & 2 & 2 & 0.12 \\
\hline & RD0605 & 2 & 2 & 0.48 \\
\hline & RD0607 & 2 & 2 & 0.12 \\
\hline & RD0610 & 2 & 2 & 0.12 \\
\hline \multirow[t]{6}{*}{7} & RD0701 & 2 & 2 & 0.32 \\
\hline & RD0702 & 2 & 2 & 0.12 \\
\hline & RD0703 & 2 & 2 & 0.13 \\
\hline & RD0707 & 2 & 2 & 0.15 \\
\hline & RD0708 & 2 & 2 & 0.50 \\
\hline & RD0709 & 2 & 1 & 0.06 \\
\hline \multirow[t]{3}{*}{8} & RD0806 & 2 & 2 & 0.39 \\
\hline & RD0807 & 2 & 2 & 0.48 \\
\hline & RD0812 & 2 & 2 & 0.12 \\
\hline \multirow[t]{2}{*}{9} & RD0904 & 2 & 2 & 0.44 \\
\hline & RD0909 & 2 & 2 & 0.48 \\
\hline \multirow[t]{3}{*}{10} & RD1002 & 2 & 2 & 0.49 \\
\hline & RD1008 & 2 & 2 & 0.44 \\
\hline & RD1009 & 2 & 2 & 0.23 \\
\hline \multirow[t]{3}{*}{11} & RD1101 & 2 & 2 & 0.12 \\
\hline & RD1106 & 2 & 2 & 0.28 \\
\hline & RD1111 & 2 & 2 & 0.49 \\
\hline \multirow[t]{5}{*}{12} & RD1202 & 2 & 1 & 0.29 \\
\hline & RD1208 & 2 & 1 & 0.48 \\
\hline & RD1209 & 2 & 2 & 0.32 \\
\hline & Total & 88 & 85 & \\
\hline & Average & 2 & 1.9 & 0.3 \\
\hline
\end{tabular}

151 clearly visible bands. Of 99 InDel markers, 44 (44.44\%) were polymorphic and identified a total of 88 bands and on average 2 bands per marker (Table 2). Our result was similar to that reported by Patel et al (2014), with an average number of 4.42 DNA bands for colored and white rice. The InDel PIC scores ranged from 0.06 to 0.50 , with an average of 0.30 and the genetic similarity values ranged from 0.64 to 1.00 (Table 2). The frequency of each amplified band ranged from 0.06 (present in 1 of 15 cultivars) to 0.93 (present in 14 of 15 cultivars) (Figure 2). Since rice is a self-pollinating species, most genes are normally in the homozygous form. Twelve of 99 InDel loci were found to contain heterozygous genotypes, which may be due to pollen contamination in the rice seeds. Among these 12 InDel loci, rice cultivar Chinat 1 is heterozygous in 10 loci. This result suggested that the purity of Chinat1, used in this study, was unsatisfactory. Almost half (44/99) of the InDel markers used in this study detected polymorphic DNA bands that were suitable for diversity studies. The discriminating power of the PIC scores of InDel markers was considered high and the markers were informative to discriminate the samples from each other. There were 13 InDel markers that produced specific DNA bands to one rice cultivar. The InDel markers RD0102 and RD0410 identified specific DNA bands to Jao Hom Nin; RD0112 to RD8, RD0211; RD0305 to Chainat1; RD0504 to Supanburi3; RD0607 to RD41, RD0601, RD0602; RD0610 to Supanburi60; and RD0707 and RD1101 to Pathumtani1 (Figure 2). These markers can be used to identify a variety or for hybrid screening in a rice breeding program.

\section{Genetic relationship analysis}

Forty-four InDel markers, used to analyze the genetic relationships, allowed the discrimination and identification of 14 of 15 rice cultivars. Two cultivars (KDML105 and RD6) could not be distinguished from each other. One possible explanation for this is that RD6 was developed from KDML105 by gamma radiation mutation. Genetically they were more than 99\% identical. RD6 has almost the same genetic background as KDML105, except that RD6 is glutinous and KDML105 non-glutinous rice. The $\operatorname{waxy}(W x)$ gene regulates the quantitative level of the Wx protein and the amylose content. RD6 has a low $(0 \%)$ but KDML a high amylose content (16\%) (Wanchana et al. 2003). The genetic relationships among all rice cultivars were analyzed and observed by cluster analysis (UPGMA) based on Euclidean distances, by which dissimilarities between the studied rice cultivars were highlighted. Three major groups consisted of 2, 9 and 4 rice cultivars, separated at a similarity index value of 0.758 (Figure 3 ). 


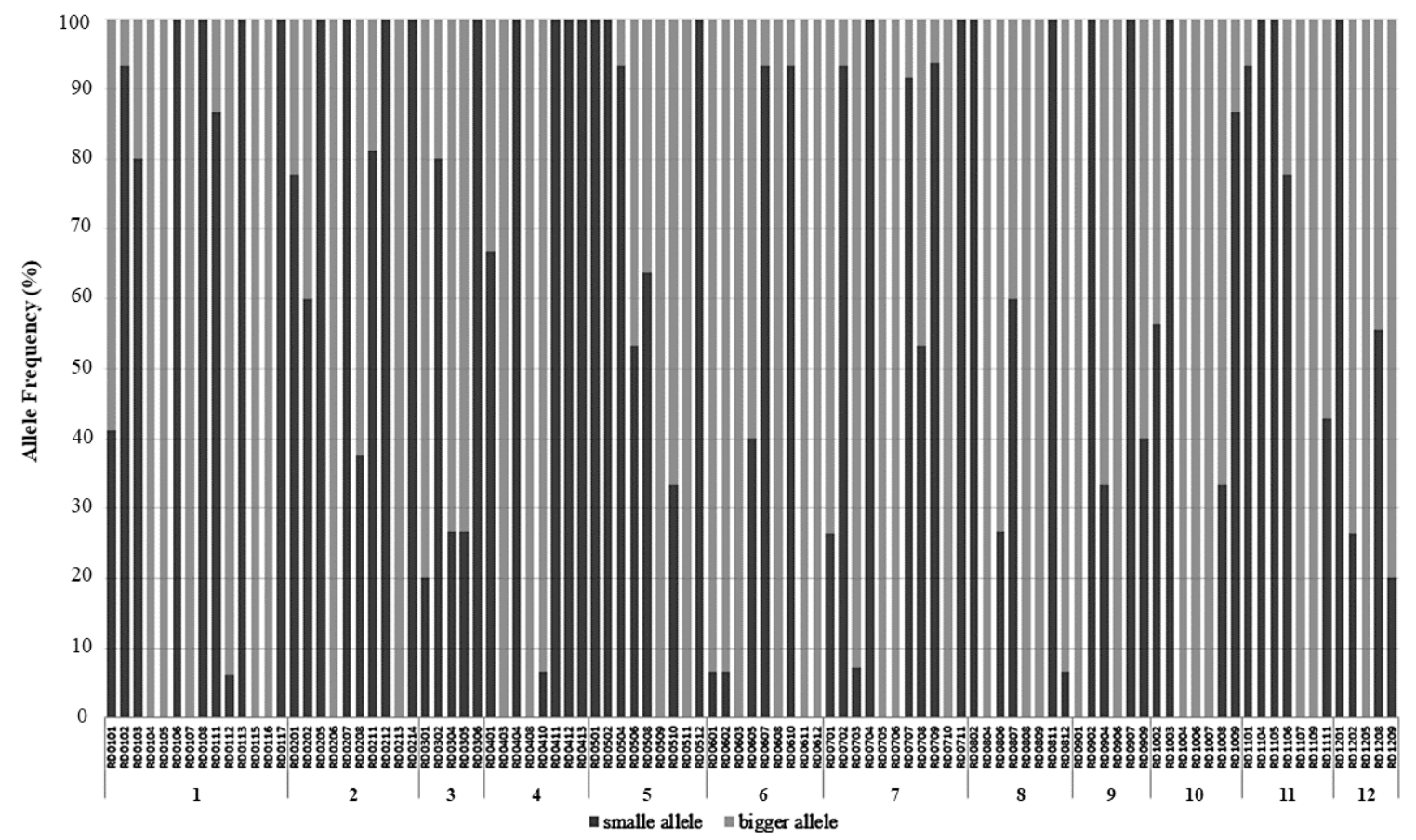

Figure 2. Allele frequency distribution of 99 InDel markers on 12 rice chromosomes.

The first major group consisted of two cultivars, namely Chainat1 and Suphanburi3, which were clearly divergent from the rest. The second major group consisted of nine cultivars with two sub-groups. Sub-group A consisted of three cultivars, i.e., Suphanburi1, RD31 and RD41. Sub-group B consisted of six cultivars, including Pissanulok2, RD49, RD47, Pathumthani1, Suphanburi60 and Jao Hom Nin. The third major group was formed by four cultivars, which were KDML105, RD6, RD8 and Niaw Ubon1. The rice cultivars RD8 and NeawUbon1 were placed close to each other, with a genetic similarity of 0.83 . The reason is that these two rice cultivars were generated from the same parental cross, Niawsaphatong2 and IR262. Nei's gene diversity index among cultivars was 0.3542 , which indicated the moderate level of gene diversity. The gene diversity within cultivars could not be calculated because each cultivar was represented by pooled DNA.

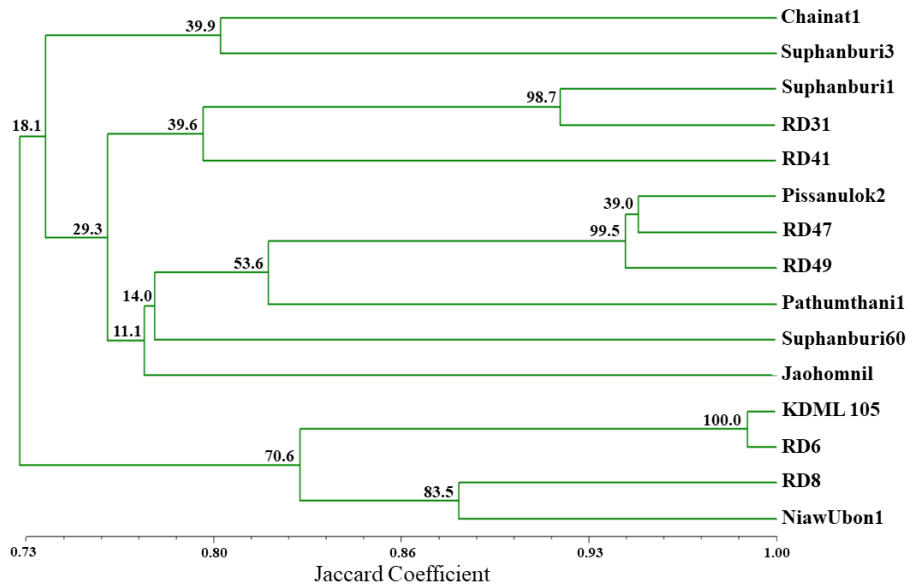

Figure 3. Dendrogram of the relationships of InDel markers of 15 Thai rice cultivars based on UPGMA cluster analysis. 


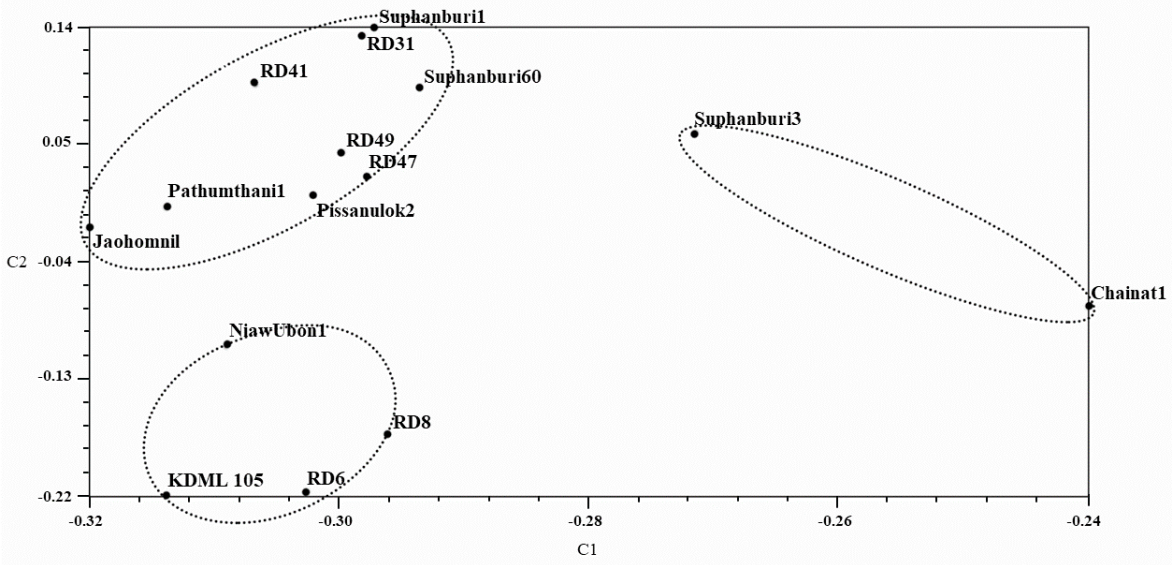

Figure 4. Principal component analysis (PCA) for InDel markers of 15 Thai rice cultivars.

The InDel markers RD0305 and RD0806 detected DNA bands specific to rice cultivars in major group 3, which were photoperiod-sensitive and can only be harvested once a year (main-season rice) (Rice Department of Thailand 2017). The major genes Ehd1 (located on chromosome 3 between microsatellite markers RM3230 and RM3372) and Hd1 (located on chromosome 6 near microsatellite marker RM8225 (Subudhi et al. 2018) control the response to photoperiod in rice (Yano et al. 2001, Subudhi et al. 2018). In this study, InDel marker RD0302 could detect the polymorphism for Ehd1 gene and RD0605 the polymorphism for Hd1 gene. However, Analysis of Molecular Variance (AMOVA) showed that the genetic diversity between cultivars (94\%) was much higher than when the rice cultivars were classified by the photoperiod response (6\%). This result suggested that even though these InDel markers could be used to identify rice cultivars based on their photosensitivity, they do not reflect the level of genetic diversity within the group. Our result demonstrated that InDel markers could be used for the screening or selection of genes controlling trait of interests in rice breeding programs.

InDel marker RD0605 detected a specific DNA band to rice cultivars in the major group 2. InDel marker RD0302 detected a specific DNA band to sub-group A in the major group 2 and RD0103 a specific DNA band to sub-group B in the major group 2. Principal component analysis (PCA) was performed to discriminate the rice cultivars and to further confirm the clustering pattern derived from the phylogenetic tree (Figure 4). The first two axes explained $72.11 \%$ of the cumulative molecular variance among accessions, with PCO 1 accounting for $64.35 \%$ and PCO 2 for $7.76 \%$. Our overall results confirmed that InDel markers are useful and can be used successfully for the genetic analysis of rice. The genetic variation information generated from this study will serve as important information for the sustainable rice breeding program in Thailand.

\section{ACKNOWLEDGEMENTS}

This research was funded by a graduate scholarship of the National Research Council of Thailand (NRCT) in 2018 and Miss Pattaraborn Moonsap was supported by graduate scholarships of the Graduate School of Kasetsart University and the Bilateral Research Cooperation, Faculty of Science, Kasetsart University.

\section{REFERENCES}

Anderson JA, Churchill GA, Autrique JE, Tanksley SD and Sorrells ME (1993) Optimizing parental selection for genetic linkage maps. Genome 36: 181-186.

Barrett BA, Kidwell KK and Fox PN (1998) Comparison of AFLP and pedigree based genetic diversity assessment methods using wheat cultivars from the Pacific Northwest. Crop Science 38: 1271-1278.
Bhattramakki D, Dolan M, Hanafey M, Wineland R, Vaske D, Register IJC, Tingey SV and Rafalski A (2002) Insertion-deletion polymorphisms in 3 ' regions of maize genes occur frequently and can be used as highly informative genetic markers. Plant Molecular Biology 48: 539-547.

Britten RJ, Rowen L, Williams J and Cameron RA (2003) Majority of divergence between closely related DNA samples is due to indels. Proceeding of National Academy of Science USA 100: 4661-4665. 
Doyle JJ and Doyle JL (1987) A rapid DNA isolation procedure for small quantities of fresh leaf tissue. Phytochemical Bulletin 19: 11-15.

Fufa H, Baenziger PS, Beecher I, Dweikat V, Graybosch RA and Eskridge KM (2005) Comparison of phenotypic and molecular marker-based classifications of hard red winter wheat cultivars. Euphytica 145: 133-146.

García-Lor A, Luro F, Navarro L and Ollitrault P (2012) Comparative use of InDel and SSR markers in deciphering the interspecific structure of cultivated citrus genetic diversity: a perspective for genetic association studies. Molecular Genetics and Genomics 287: 77-94.

Hou X, Li L, Peng Z, Wei B, Tang S, Ding M, Liu J, Zhang F, Zhao Y, Gu H and Qu L (2010) A platform of high-density INDEL/CAPS markers for map-based cloning in Arabidopsis. The Plant Journal 63: 880-888.

Meyer $\mathrm{G}$ and Prasertsri P (2007) Thailand grain and feed rice crop survey 2007. USDA Foreign Agricultural Service, Gainsville, 45p. (GAIN Report Number: TH7005).

Ollitrault F, Terol J, Martin AA, Pina JA, Navarro L, Talon M and Ollitrault P (2012) Development of InDel markers from Citrus clementina (Rutaceae) BAC-end sequences and interspecific transferability in Citrus. American Journal of Botany 99: 268-273.

Patel S, Ravikiran R, Chakraborty S, Macwana S, Sasidharan N, Trivedi R and Aher B (2014) Genetic diversity analysis of colored and white rice genotypes using Microsatellite (SSR) and Insertion-Deletion (INDEL) markers. Emirates Journal of Food and Agriculture 26: 497.

Peakall R and Smouse PE (2012) GenAlEx 6.5: Genetic Analysis in Excel. Population Genetic Software for teaching and Research-An Update. Bioinformatics 28: 2537-2539.
Raman H, Raman R, Wood R and Martin P (2006) Repetitive Indel markers within the ALMT1 gene conditioning aluminium tolerance in wheat (Triticum aestivum L.). Molecular Breeding 18: 171-183.

Rohlf FJ (2000) NTSYSpc: Numerical taxonomy and multivariate analysis system. Version 2.02, Exeter Software, New York, USA.

Sneath PH and Sokal RR (1973) Numerical Taxonomy: The principles and practice of numerical classification. W. H. Freeman, San Francisco, 268p.

Subudhi PK, De Leon TB, Tapia R, Chai C, Karan R, Ontoy J and Singh PK (2018) Genetic interaction involving photoperiod-responsive $h d 1$ promotes early flowering under long-day conditions in rice. Scientific Reports 8: 2081.

Thai Rice Exporters Association (2018) World market \& trade, USDA. Available at: <http://www.thairiceexporters.or.th/world\%20rice\%20 trade>. Accessed on Jan 30, 2018.

Wanchana S, Toojinda T, Tragoonrung S and Vanavichit A (2003) Duplicated coding sequence in the waxy allele of tropical glutinous rice (Oryza sativa I.). Plant Science 165: 1193-1199.

Wu DH, Wu HP, Wang CS, Tseng HY and Hwu KK (2013) Genome-wide InDel marker system for application in rice breeding and mapping studies. Euphytica 192: 131-143.

Yano M, Kojima S, Takahashi Y, Lin H and Sasaki T (2001) Genetic control of flowering time in rice, a short-day plant. Plant Physiology 127: 1425-1429.

Yeh FC and Yang RC (1999) POPGENE version 1.32. University of Alberta and Tim Boyle, Centre for International Forestry Research. 